\title{
Les rites dans l'entreprise de Jean-Pierre Jardel et Christian Loridon, Les Echos Editions et Editions d'organisation, Paris, 2000, 274 pages
}

\section{Hugues Hotier}

\section{(2) OpenEdition}

\section{Journals}

Édition électronique

URL : http://journals.openedition.org/communicationorganisation/2388

DOI : 10.4000/communicationorganisation.2388

ISSN : 1775-3546

Éditeur

Presses universitaires de Bordeaux

\section{Édition imprimée}

Date de publication : 1 mai 2000

ISSN : 1168-5549

\section{Référence électronique}

Hugues Hotier, "Les rites dans l'entreprise de Jean-Pierre Jardel et Christian Loridon, Les Echos Editions et Editions d'organisation, Paris, 2000, 274 pages ", Communication et organisation [En ligne], 17 | 2000, mis en ligne le 27 mars 2012, consulté le 19 avril 2019. URL : http://journals.openedition.org/ communicationorganisation/2388 ; DOI : 10.4000/communicationorganisation.2388

Ce document a été généré automatiquement le 19 avril 2019

(C) Presses universitaires de Bordeaux 


\title{
Les rites dans l'entreprise de Jean- Pierre Jardel et Christian Loridon, Les Echos Editions et Editions d'organisation, Paris, 2000, 274 pages
}

\author{
Hugues Hotier
}

1 Voilà un ouvrage qui se lit vite. D'abord parce que les marges sont larges et que la typographie recourt à un corps important. En d'autres termes, on pouvait sans doute faire de substantielles économies sur le papier et réduire le volume de moitié. Il est vrai que la marge permet de présenter, en gras sur fond tramé, l'essentiel de ce que dit le texte; ultime facilitation pour lecteur vraiment pressé... Et le moins qu'on puisse dire est que cet essentiel est lapidaire : "D'une manière générale, les rites de passage rythment le déroulement de la vie humaine. » (p. 55) ou «Le CV est bien un document rituel » ou encore «Dans le système capitaliste, le temps est devenu une valeur et un bien de consommation.». Sans aller plus loin dans la comparaison, on retrouve là les configurations chères à la presse à sensation dont les mises en page permettent d'entrer dans le texte de différentes façons selon le temps dont on dispose.

2 Jean-Pierre Jardel et Christian Loridon sont des spécialistes du temps. Le premier le traite $\mathrm{du}$ point de vue du chercheur en sociologie et anthropologie des organisations. Le second en tant que consultant spécialisé dans les questions de gestion du temps. C'est donc par ce biais que les rituels sont approchés dans cet ouvrage sous-titré Une nouvelle approche $d u$ temps.

3 L'idée qui sous-tend ce livre est que l'entreprise est un milieu sur lequel l'ethnologue, l'anthropologue, ou l'ethno-anthropologue dont il est ici beaucoup question dans les premières pages, peuvent à bon droit poser un regard. D'où une analogie entre ce que les travaux des ethnologues et des anthropologues nous ont appris et ce que «l'ethno- 
anthropologue d'entreprise» (p. 19) peut observer: «Par analogie, le rite d'initiation des jeunes garçons en Afrique se retrouve chez les étudiants et les apprentis. "...

4 D'aphorismes en mises en garde frappées au coin d'un solide bon sens, cette pure description progresse comme une parfaite illustration de la citation de Saint Augustin qui figure en exergue du premier chapitre et qui pourrait aussi bien se trouver en dernière page, à titre de conclusion de l'ouvrage : "Qu'est-ce donc que le temps? Si personne ne me le demande, je le sais, mais si on me le demande et que je veuille l'expliquer, je ne sais plus. ॥.

5 Le sujet est intéressant, la publicité insérée dans Le Monde alléchante, j'ai acheté le livre les yeux fermés. Je ne vous conseille pas de m'imiter. 